\title{
The synergy between medicine and mechanical engineering
}

\begin{abstract}
The current scientific production requires a series of capacities, not only referring to the necessary knowledge of the specialty area. It is also necessary to manage several methods and methodologies to carry out the various research processes. In the Medical-Biological area, the synergy between different sciences has been necessary for its advances, being one of the main established with Mechanical Engineering where the methods used by Mechanics have allowed to improve those used in Medicine.
\end{abstract}

Volume 3 Issue $3-2019$

\author{
Rosa Alicia Hernández-Vázquez, Rodrigo \\ Arturo Marquet-Rivera, Octavio-Alejandro \\ Mastache-Miranda, Luis-Javier Hernández- \\ Mora, Guillermo Urriolagoitia-Sosa, Beatriz \\ Romero-Ángeles, Guillermo Urriolagoitia- \\ Calderón \\ Instituto Politécnico Nacional, México
}

\begin{abstract}
Correspondence: Rosa Alicia Hernández-Vázquez, Instituto Politécnico Nacional, Escuela Superior de Ingeniería Mecánica y Eléctrica, Sección de Estudios de Posgrado e Investigación Unidad Profesional Adolfo López Mateos, Zacatenco. Av. IPN s/n Edificio 5, $2^{\circ}$ piso Col. Lindavista, Delegación Gustavo A. Madero, C.P. 07320, México, Email ra.hernandez.vazquez@gmail.com
\end{abstract}

Received: May 13, 2019 | Published: May 29, 2019

\section{Introduction}

Traditionally, Exact Sciences are divided into Physics, Chemistry and Biology. Their fields of action were apparently very limited, so that the interaction between them was not considered common. However, each of the fields that constitute them present issues that compete. It is not possible to study the cell, without talking about the chemical processes inherent in its metabolism or respiration, as well as studying the processes of nutriment transportation through its physical barrier, the cell membrane. In this way, science such as Biochemistry or Physical Biology emerged. ${ }^{1}$

As more discoveries were made around the interaction of Exact Sciences, in addition to new fields, new areas were generated that allowed to acquire a greater understanding of the macro and microcosm, as well as having the instrumental means that gave rise to the new discoveries of humanity (the microscope thanks to optics, a Physics area, to study the basic unit of any biological being, the cell). Currently, in addition to these sciences that arose from the interaction between them, multidisciplinary research has allowed generating and provide solutions to issues that were believed to be exclusive of certain sciences without deriving from each other. ${ }^{2}$ One example is the synergy that emerges from Medicine (a branch of Biology) and Mechanical Engineering (a branch of Physics), through which various questions and medical phenomena have been answered using Engineering methodologies.

Just as the movement of the stars can be calculated and simulated by computer programs commonly used in Engineering, phenomena such as blood circulation it is possible to reproduce and simulate with these programs mainly those that use the Finite Element Method (FEM) (Figure 1).

The movements of the articulations of the Skeletal System are studied and analyzed as it is done to the different Mechanisms of the robots of the assembly lines (Figure 2). The various biological tissues can be studied with these programs to represent health and disease states due to their own physiology, as is done to determine faults and periods of useful life in machines.

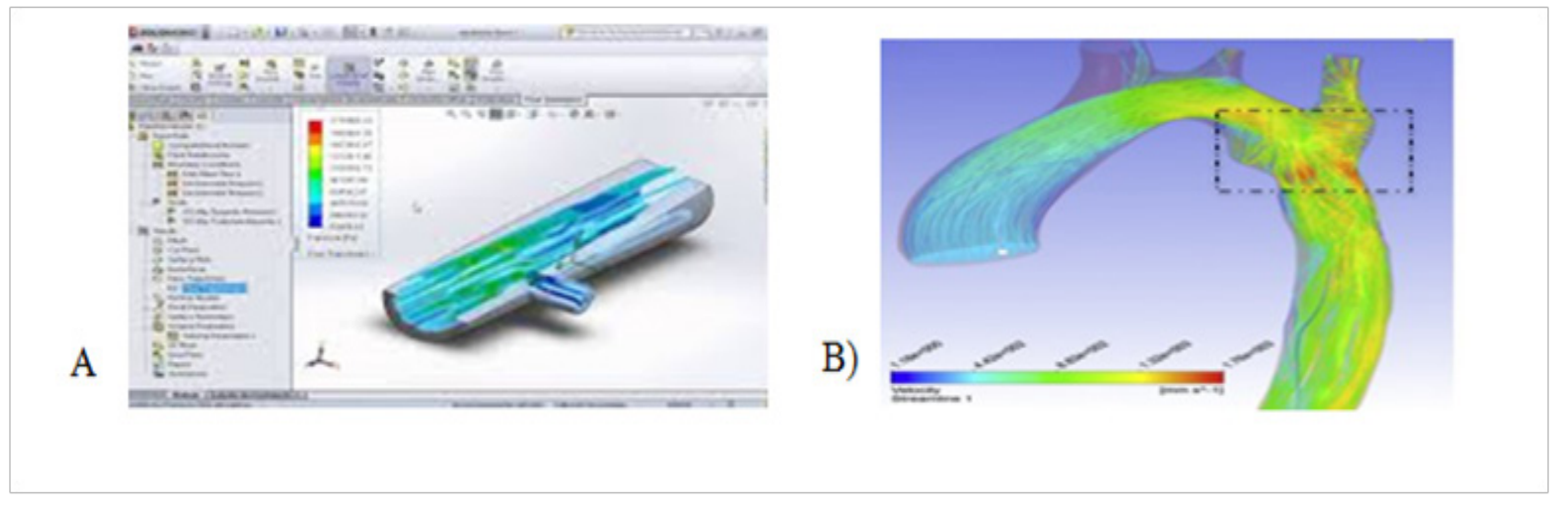

Figure I Numerical simulation using FEM:A) Water flow in a pipe, B) Blood flow in an artery. 


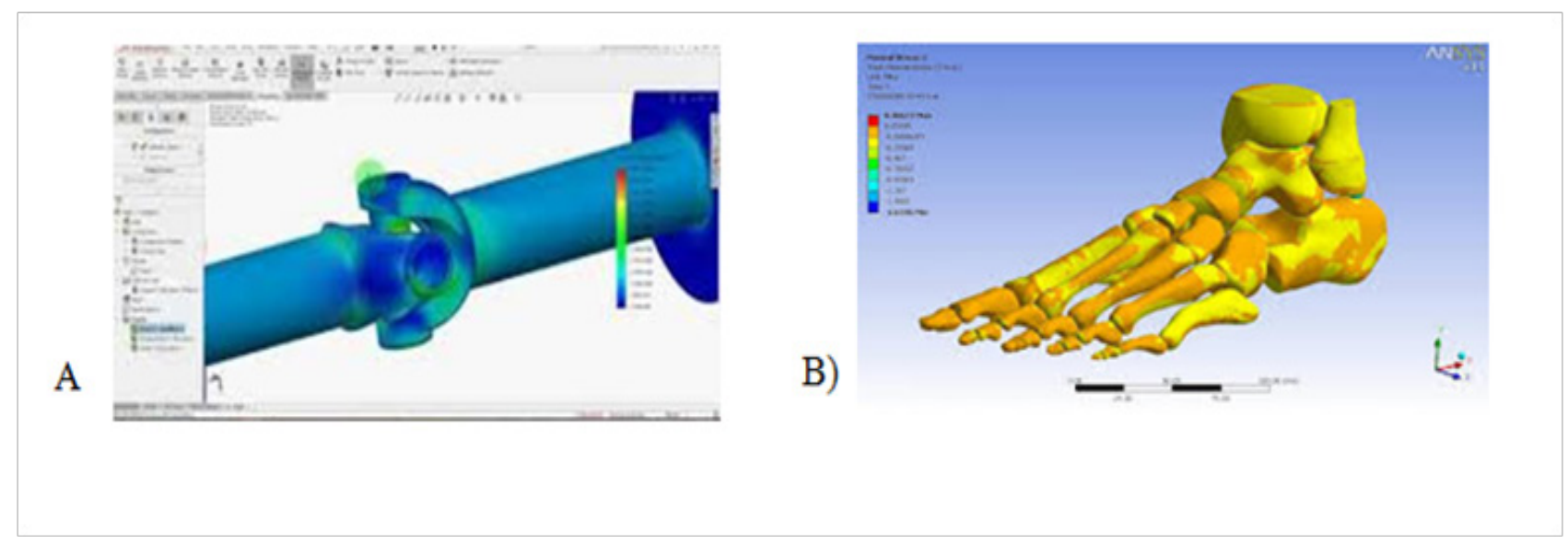

Figure 2 Numerical simulation using FEM:A) Robotic arm articulation, B) Human articulations.

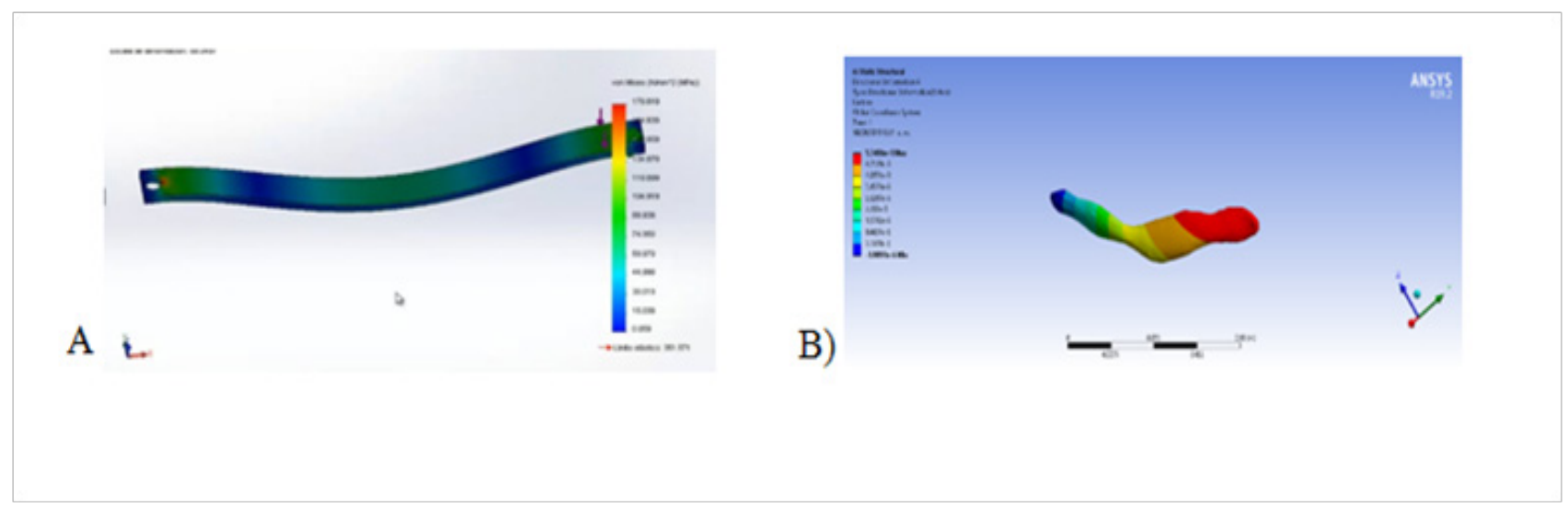

Figure 3 Numerical simulation using FEM:A) Rubber band, B) Human ligament.

\section{Conclusion}

Nowadays the task of science requires that you have a baggage of different knowledge, not necessarily exclusive of the area of expertise. For a while, now it is well known that a high degree of specialization in any field, is no longer ideal. The capacity of inter and multidisciplinary turns out to be more desirable for the development of new sciences and technologies. The synergy between the different sciences is fundamental for the development of this capacity. Therefore, in the case of the Medical-Biological Sciences, the synergy with Mechanical Engineering is fundamental.

\section{Acknowledgments}

The authors gratefully acknowledge the Instituto Politécnico Nacional and the Consejo Nacional de Ciencia y Tecnología.

\section{Conflicts of interest}

Author declares their are no conflicts of interest.

\section{References}

1. Uversky VN. Dancing protein clouds: the strange biology and chaotic physics of intrinsically disordered proteins. $J$ Biol Chem. 2016;291(13):6681-6688.

2. Hernández Vazquez RA, Romero Ángeles B, Urriolagoitia Sosa, et al. Training for research and scientific education in dentistry through the use of numerical simulation. 2019;23(3). 